\title{
Structure-Activity Studies and Analgesic Efficacy of N-(3-Pyridinyl) Bridged Bicyclic Diamines, Exceptionally Potent Agonists at Nicotinic Acetylcholine Receptors
}

\author{
William H. Bunnelle ${ }^{+*}$, Jerome F. Daanen ${ }^{+}$, Keith B. Ryther ${ }^{+}$, Michael R. Schrimpf ${ }^{+}$, Michael J. Dart ${ }^{+}$, \\ Arianna Gelain”, Michael D. Meyer ${ }^{+}$, Jennifer M. Frost ${ }^{+}$, David J. Anderson ${ }^{+}$, Michael Buckley ${ }^{+}$, Peter \\ Curzon $^{+}$, Ying-Jun $\mathrm{Cao}^{+}$, Pamela Puttfarcken ${ }^{+}$, Xenia Searle ${ }^{+}$, Jianguo $\mathrm{Ji}^{+}$, C. Brent Putman ${ }^{+}$, Carol \\ Surowy ${ }^{+}$, Lucio Toma ${ }^{\ddagger}$, Daniela Barlocco ${ }^{\#}$
}

\section{Supporting Information}

Assessment of enantiomeric purity for S-9 and R-9: Enantiomeric purities of the 2,5diazabicylco[2.2.1] heptanes were inferred from chiral HPLC of samples of Boc-S-8 and Boc-R-8, prepared separately from S-9 and R-9, respectively. Baseline resolution of these enantiomers was achieved on a Chiralcel OD-H ${ }^{\mathrm{TM}}$ column, as shown below:

$0.46 \times 15 \mathrm{~cm}$ Chiralcel OD-H ${ }^{\mathrm{TM}}$ column

Hexanes-iPA (90:10), $1 \mathrm{~mL} / \mathrm{min}$

$\mathrm{UV}$ detection at $254 \mathrm{nM}$ (peak area \% listed)

Based upon peak area measurements, Boc-S-8 and Boc-R-8 are each greater than 99\% enantiomerically pure. 
Boc-S-8
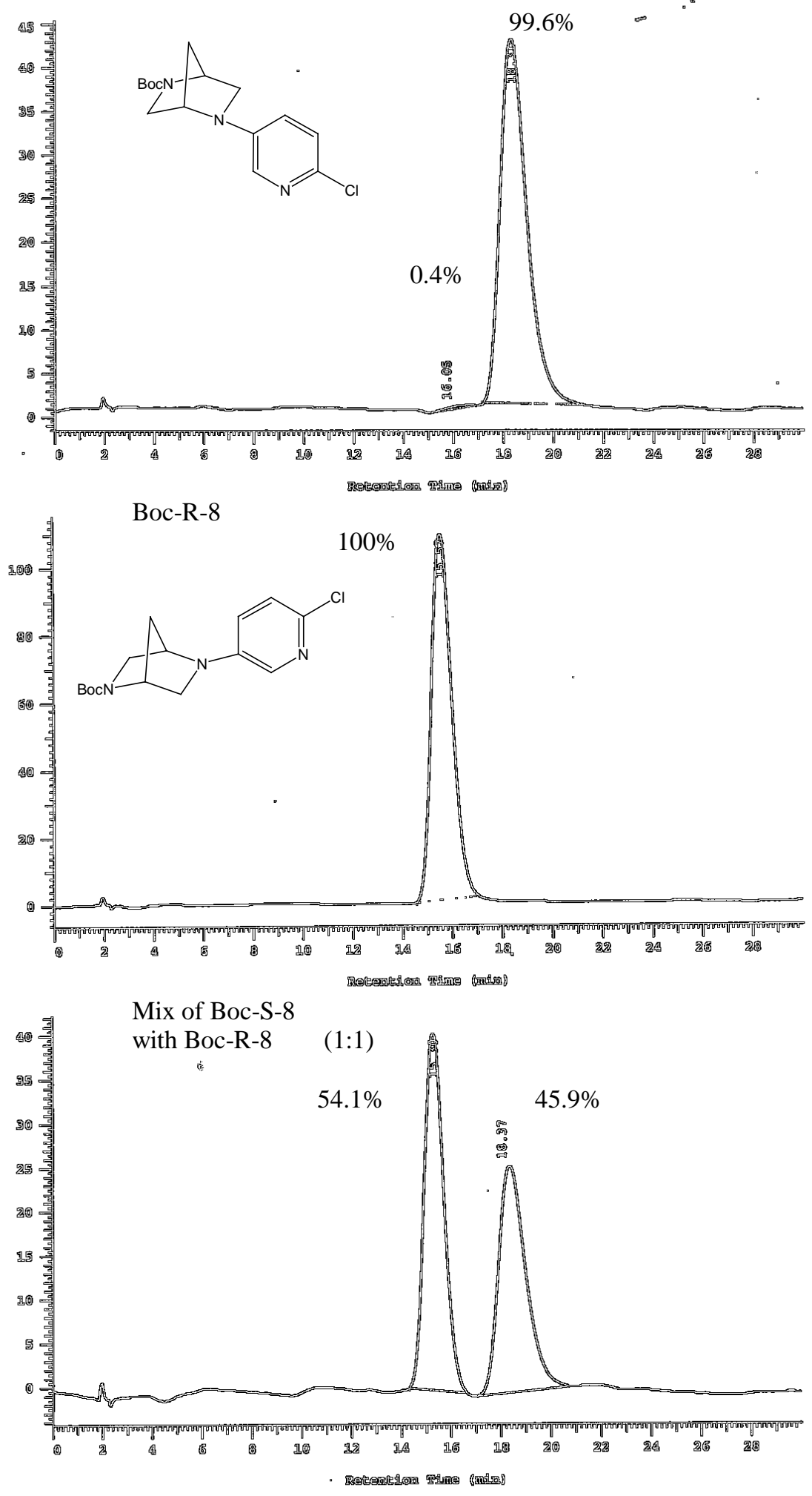


\section{Evaluation of brain-plasma distribution of 8R-k following ip dosing in rat:}

Male Sprague-Dawley rats ( $\mathrm{n}=3$ animals per group).

Maximum brain and plasma levels of $\mathbf{R}-\mathbf{4 4}$ are measured at $15 \mathrm{~min}$, and both

concentrations decrease in parallel over tp the $1 \mathrm{~h}$ time point. The [brain]/[plasma] ratio of $\mathbf{R}-\mathbf{4 4}$ remains between $0.06-0.08$ at all three timepoints.

\section{Plasma and brain levels of R-44 following}

$6.2 \mu \mathrm{mol} / \mathrm{kg}$, i.p. dose in rat

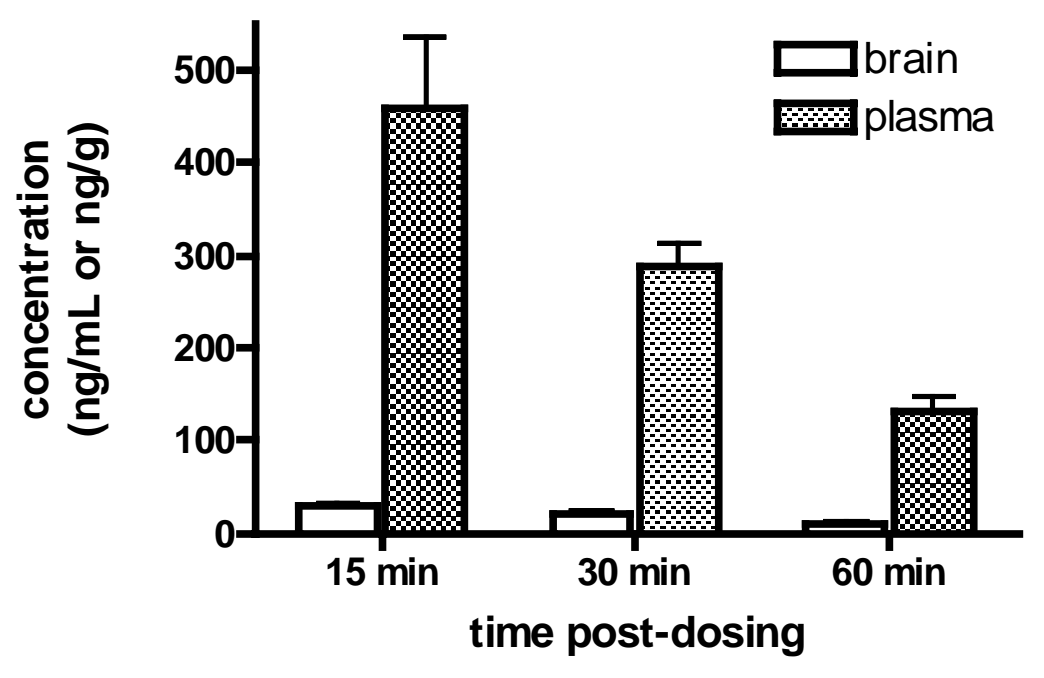

$\begin{array}{llll} & 15 \mathrm{~min} & 30 \mathrm{~min} & 60 \mathrm{~min} \\ \text { brain level }(\mathrm{ng} / \mathrm{g}) & 29 \pm 3 & 22 \pm 2 & 10 \pm 4 \\ \text { plasma level }(\mathrm{ng} / \mathrm{mL}) & 458 \pm 77 & 289 \pm 23 & 131 \pm 16\end{array}$


Effect of the nAChR antagonist mecamylamine on the antinociceptive effect of S-8

in the rat hot box: Pretreatment (ip) with saline (left-hand side of graph) or

mecamylamine ( $5 \mu \mathrm{mol} / \mathrm{kg}) 10$ min prior to administration of saline (solid bars) or $\mathbf{S - 8}$

$(0.62 \mu \mathrm{mol} / \mathrm{kg}$, hatched bars $) ; \mathrm{n}=6 /$ group. The antinociceptive effect of $\mathbf{S - 8}$ is

completely blocked (indistinguishable from saline) by pretreatment with the nicotinic antagonist mecamylamine.

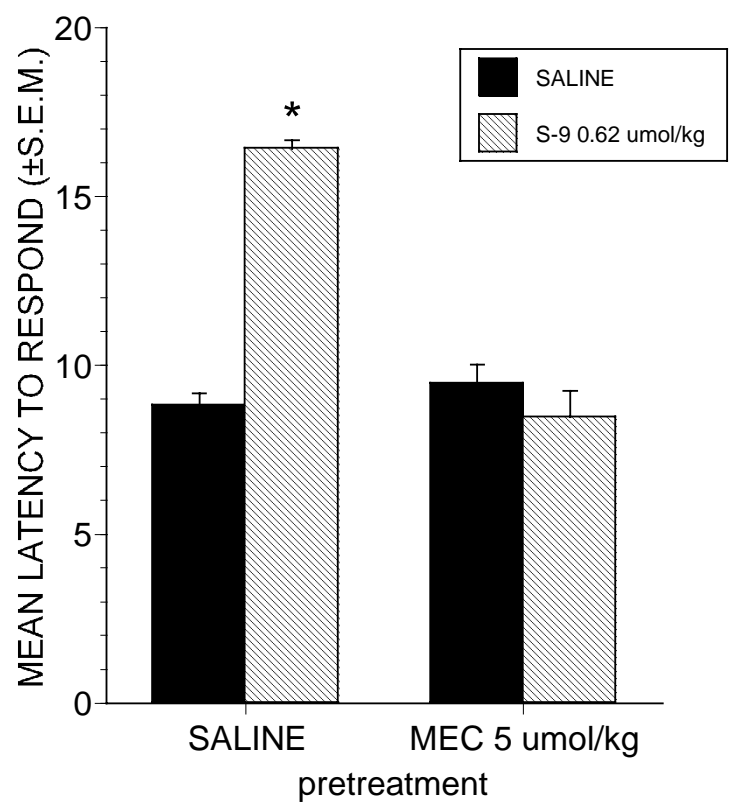

